\title{
Government Expenditures, Transfer Payments and Economic Growth
}

\author{
Lai Yue ${ }^{\mathrm{a}}$, Cheng Tianzhu ${ }^{\mathrm{b}}$ \\ Financial and Economic Department, Guangxi University of Technology, Liuzhou, Guangxi 545006, \\ P.R.China
}

\begin{abstract}
Incorporating a two-level government structure into an endogenous growth model, we distinguished between productive and non-productive government expenditures. With transfer payments considered, we showed that (1) there was an "Inverted U-shaped" relationship between the tax rate and the long-run economic growth, so was the relationship between the degree of fiscal decentralization and the long-run economic growth; (2) optimal ratios between productive and non-productive expenditures of two levels of governments, between transfer payments and other parts of expenditures of the state-level governments are needed to maximize the long-run economic growth.
\end{abstract}

Index Terms: government expenditures; transfer payments; fiscal decentralization; economic growth

(C) 2012 Published by MECS Publisher. Selection and/or peer review under responsibility of the Research Association of Modern Education and Computer Science.

\section{Introduction}

The relationship between government expenditures and economic growth has been long in research. Reference [1] initially found a significant positive relationship between total government expenditures and the output. Reference [2] examed the impacts of government expenditures on consumption and capital accumulation to the output separately and found that government expenditures on consumption has a smaller while still positive impact on the output. On the basis of this paper, Reference [3] incorporated government expenditures into the standard endogenous growth model which was traced to [4]. The empirical study in [3] provided ambiguous conclusions on the impacts of different parts of government expenditures on the output. Reference [5] distinguished between productive and non-productive government expenditures, by using a panal data of 43 developing countries they found a short-term positive while a long-term negative impact of productive expenditures on the output. Reference [6] paid attention to the impacts of different government structures on the economy, while the empirical study of them was criticized by [7] about the time span of the panal data they used.

\footnotetext{
* Corresponding author.

E-mail address: ${ }^{\mathrm{a} l u n a l a i y u e} @ 163 . c o m ;{ }^{\mathrm{b}} 13978096992 @ 163 . c o m$
} 
The above papers provided valuable insights into the relationship between government expenditures and economic growth. Distinguishing between productive and non-productive government expenditures is needed as their impact are different in a short term. Also, government structures should be considered if there are differences among the contributions of each level government expenditures to the output. In this paper we established an endogenous growth model extended from [8] and incorporated a two-level government structure and transfer payments into it. Section II was the description of this model. In section III, we examed the impacts of some factors on the long-run economic growth using the comparative static analysis. Section IV concluded this paper.

\section{The Basic Model}

\subsection{Government Structures}

In a closed economy with only governments and identical economic agents, government expenditures are supposed to maximize the consumer welfare. Here in the basic model, government structures are important because productivety may be different related with each level government expenditures. Two levels, government of the state-level and the local-level, are supposed for simplicity. Government expenditures are divided consequently into those from the state-level government and from the local-level governments, $f$ denoted the former and $S$ the latter.

According to [3], some government expenditures are productive, such as infrastration and government purchase, others are non-productive in a short term. Non-productive expenditures conclude those expensed in national defense, basic education, health care, local medical services, etc. Here, let $f_{k}$ and $f_{c}$ be the productive expenditures and non-productive expenditures from the state-level government respectively, $s_{k}$ and $s_{c}$ be the productive expenditures and non-productive expenditures from the local-level government. Total government expenditures $g$ are denoted by

$$
g=f_{k}+f_{c}+s_{k}+s_{c}
$$

A balanced budget requirs

$$
g=\tau y
$$

here $\tau$ is the total tax shared by the governments of two levels with a portion of $\varphi_{1}$ goes to the state-level government and a portion of $\varphi_{2}$ to the local-level government, $\varphi_{1}+\varphi_{2}=1$ is satisfied. A transfer payment $T$ will be given by the higher-level government to the lower-level government for the purpose of equity. Then budget constraints of the state-level government are

$$
f_{k}+f_{c}=\phi_{1} \tau y-T
$$

and of the local-level government are

$$
s_{k}+s_{c}-T=\phi_{2} \tau y
$$

In order to distinguish productive expenditures from non-productive ones, we use $\theta_{i} \in[0,1]$ to denote different part of government expenditures as 


$$
f_{k}=\theta_{1} \phi_{1} \tau y, f_{c}=\theta_{2} \phi_{1} \tau y, T=\theta_{3} \phi_{1} \tau y
$$

with $\sum \theta_{i}=1, \quad i=1,2,3$ satisfied, and also we have

$$
\begin{aligned}
& s_{k}=\varepsilon_{1}\left(\phi_{2} \tau y+T\right)=\varepsilon_{1}\left(\phi_{2}+\theta_{3} \phi_{1}\right) \tau y \\
& s_{c}=\varepsilon_{2}\left(\phi_{2} \tau y+T\right)=\varepsilon_{2}\left(\phi_{2}+\theta_{3} \phi_{1}\right) \tau y
\end{aligned}
$$

with $\sum \varepsilon_{i}=1, i=1,2$ satisfided.

\subsection{The Behavior of Consumers}

An infinitely lived consumer consumes products and services provided by individuals and governments at a given time to maximize its lifetime utility. The consumer's lifetime utility function takes the form

$$
U\left(c, f_{k}, f_{c}, s_{k}, s_{c}\right)=\int_{0}^{\infty} u\left(c, f_{k}, f_{c}, s_{k}, s_{c}\right) e^{-\rho t} d t
$$

$u\left(c, f_{k}, f_{c}, s_{k}, s_{c}\right)$ is the instantaneous utility fuction of identical consumers and $0<\rho<1$ is the discount rate in (8).. For simplicity and without loss of generality, let

$$
u\left(c, f_{k}, f_{c}, s_{k}, s_{c}\right)=\ln c+\sigma_{k}^{f} \ln f_{k}+\sigma_{c}^{f} \ln f_{c}+\sigma_{k}^{s} \ln s_{k}+\sigma_{c}^{s} \ln s_{c}
$$

here $\sigma_{k}^{f}, \sigma_{c}^{f}, \sigma_{k}^{s}$ and $\sigma_{c}^{s}$ are nonnegative parameters.

Production in the economy is an Cobb-Doglas function of private investment $k$ and government expenditures as

$$
f\left(k, f_{k}, f_{c}, s_{k}, s_{c}\right)=k^{\beta_{1}} f_{k}^{\beta_{2}} f_{c}^{\beta_{3}} s_{k}^{\beta_{4}} s_{c}^{\beta_{5}}
$$

$\beta_{i}$ are all nonnegative parameters and $\sum \beta_{i}=1, i=1,2,3,4,5$ garantees an economy of constant renturns to scale(CRS) in (10). Given (2), (8) and (10), a simple caculation yields

$$
\dot{k}=(1-\tau) y-c
$$

Consumers will maximize his utility function (8) subject to the production function (10) and private investment growth constraints (11).

\subsection{The Balanced Growth Path}

Constructing relevant Hamilton function of this model provides the constant growh rate on the balanced growh path, i.e. the steady-state growh rate, as 


$$
G=\beta_{1}(1-\tau) \tau^{\left(1-\beta_{1}\right) / \beta_{1}}[\bullet]^{1 / \beta_{1}}-\rho
$$

Here (12) satisfies

$$
[\bullet]=\left(\theta_{1} \phi_{1}\right)^{\beta_{2}}+\left(\theta_{2} \phi_{1}\right)^{\beta_{3}}+\left[\varepsilon_{1}\left(\phi_{2}+\theta_{3} \phi_{1}\right)\right]^{\beta_{4}}+\left[\varepsilon_{2}\left(\phi_{2}+\theta_{3} \phi_{1}\right)\right]^{\beta_{5}}
$$

Expression (12) gives the long-run economic growth rate on the balanced growth path.

\section{Comparative Static Analysis}

\subsection{The Impact of the Tax Rate}

Governments gather taxes to cover their expenditures at a tax rate $\tau$. Change in the tax rate will have an impact on the steady-state growth rate $G$. Differentiating both parts of (12) with respect to $\tau$ and evaluating the resulting expression at $\partial G / \partial \tau=0$ yields

$$
\tau^{*}=1-\beta_{1}
$$

Recalled that $\tau \in[0,1]$, and a steady-state growth rate $G^{*}$ satisfying (14) will be

$$
G^{*}=\beta_{1}^{2}\left(1-\beta_{1}\right)^{\left(1-\beta_{2}\right) / \beta_{1}}[\bullet]^{1 / \beta_{1}}-\rho
$$

where[-] is still given by (13). The impact of a change in the tax rate has two opposite effects on the long-run economic growth. Increasing the tax rate relaxed the budegt of each level government to greater expenditures, which increased the output as a result. On the other hand, increasing the tax rate eroded the disposable income of consumers, the gross consumption declined and the output went down. When the tax rate is small, the positive effect is greater, an increasing tax rate drave up the economic growth rate; while the taxation is too heavy, the negative effect is greater, an increasing tax rate drave down the economic growth rate.

The impact of the tax rate on the steady-state growth rate are showed in Fig. 1 as an "Inverted U-shape" relations. When the tax rate decreases till $\tau<\tau^{*}$, the steady-state growth rate also decreases; when the tax rate increases till $\tau>\tau^{*}$, the steady-state growth rate still decreases.

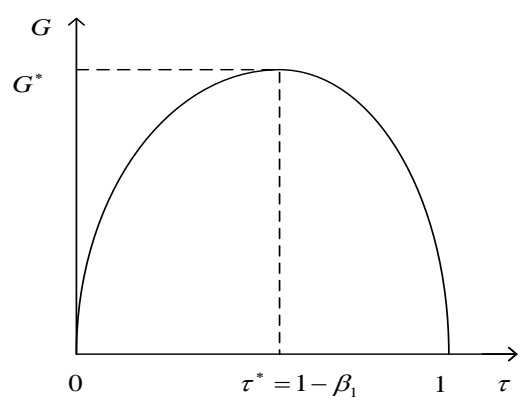

Fig.1 The impact of the tax rate 


\subsection{The Expenditure Structure of the State-level Government}

Expenditures of the state-level government include three parts, productive expenditures, non-productive expenditures and transfer payments to the local-level governments. A change about portions of these parts with total amount constant will have an impact on the growth rate on the balanced growth path.

Holding the portion of transfer payments constant, a change on the portion of productive expenditures results in an relevant opposite change of the portion of non-productive expenditures. Differentiating both parts of (12) with respect to $\theta_{1}$ and evaluating the resulting expression at $\partial G / \partial \theta_{1}=0$ yields

$$
\frac{\theta_{1}^{*}}{\theta_{2}^{*}}=\frac{\beta_{2}}{\beta_{3}}
$$

and a steady-state growth rate $G^{*}$ satisfying (16) will be

$$
G^{*}=\beta_{1}(1-\tau) \tau^{\left(1-\beta_{1}\right) / \beta_{1}}\left\{[\bullet]^{*}\right\}^{\left(1 / \beta_{1}\right)}-\rho
$$

where (17) satisfies

$$
[\bullet]^{*}=\left(\theta_{1}^{*} \phi_{1}\right)^{\beta_{2}}+\left(\frac{\beta_{3}}{\beta_{2}} \theta_{1}^{*} \phi_{1}\right)^{\beta_{3}}+\left[\varepsilon_{1}\left(\phi_{2}+\theta_{3} \phi_{1}\right)\right]^{\beta_{4}}+\left[\varepsilon_{2}\left(\phi_{2}+\theta_{3} \phi_{1}\right)\right]^{\beta_{5}}
$$

Expression (16) means that without change of transfer payments, an optimal ratio between productive expenditures and non-productive expenditures of the state-level government are needed to maximize the steadystate growth rate, which exactly equals to the ratio of their contributions to the output ( $\beta_{2}$ and $\beta_{3}$ respectively). Thence an unique emphasis on productive expenditures or non-productive expenditures will also drive down the long-run economic growth.

\subsection{The Expenditure Structure of the Local-level Government}

The expenditures of the local-level government are divided into productive and non-productive expenditures under the assumptions of the basic model. Holding total expenditures of the local-level government constant, a change of productive expenditures results in a conrresponding change in non-productive expenditures on the opposite. Differentiating both parts of (12) with respect to $\varepsilon_{1}$ and evaluating the resulting expression at $\partial G / \partial \varepsilon_{1}=0$ yields

$$
\frac{\left(\varepsilon_{1}^{*}\right)^{\left(1-\beta_{4}\right)}}{\left(\varepsilon_{2}{ }^{*}\right)^{\left(1-\beta_{5}\right)}}=\frac{\beta_{4}}{\beta_{5}}\left(\phi_{2}+\theta_{3} \phi_{1}\right)^{\left(\beta_{4}-\beta_{5}\right)}
$$

and a steady-state growth rate $G^{*}$ satisfying (19) will be

$$
G=\beta_{1}(1-\tau) \tau^{\left(1-\beta_{1}\right) / \beta_{1}}\left\{[\bullet]^{*}\right\}^{1 / \beta_{1}}-\rho
$$

where (20) satisfies 


$$
[\bullet]^{*}=\left(\theta_{1} \phi_{1}\right)^{\beta_{2}}+\left(\theta_{2} \phi_{1}\right)^{\beta_{3}}+\left[\varepsilon_{1}^{*}\left(\phi_{2}+\theta_{3} \phi_{1}\right)\right]^{\beta_{4}}+\left[\frac{\beta_{5}}{\beta_{4}}\left(\phi_{2}+\theta_{3} \phi_{1}\right)^{\left(1-\beta_{4}\right)}\left(\varepsilon_{1}^{*}\right)^{\left(1-\beta_{4}\right)}\right]^{\beta_{5} /\left(1-\beta_{5}\right)}
$$

Expression (19) determined an optimal ratio of productive expenditures and non-productive expenditures of the local-level government. If the left part of (19) is greater, a simply calculation yields $\partial G / \partial \varepsilon_{1}>0$, which means that under the conditions of a greater portion of productive expenditure of the local-level government, a transfer from the productive expenditure to the non-productive expenditure will have a positive impact on the output. Sometimes in practice, a short-sighted local-level governmet tends to expense more as productive, e.g. infrastructure, which raised the GDP in a short term but reduces the economic growth rate in a long run. On the contrary, transfering some productive resources to non-productive expenditures, e.g. local higher education and health care, will pull up the long-run economic growth rate.

\subsection{Transfer Payments}

Transfer payments are part of the income of the local-level government and of the expenditures of the statelevel government. Holding total expenditures of the state-level government constant, a change of transfer payments results in a corresponding change in productive expenditures or non-productive expenditures of the state-level government. For simplity, we assume that there will be no change in the prortion of non-productive expenditures. Differentiating both parts of (12) with respect to $\theta_{3}$ and evaluating the resulting expression at $\partial G / \partial \theta_{3}=0$ yields

$$
\theta_{3}^{*}=\frac{\beta_{4}+\beta_{5}}{\beta_{2}} \theta_{1}^{*}-\frac{\phi_{2}}{\phi_{1}}
$$

and a steady-state growth rate $G^{*}$ satisfying (22) will be

$$
G=\beta_{1}(1-\tau) \tau^{\left(1-\beta_{1}\right) / \beta_{1}}\left\{[\bullet]^{*}\right\}^{1 / \beta_{1}}-\rho
$$

where (23) satisfies

$$
[\bullet]=\left(\theta_{1}^{*} \phi_{1}\right)^{\beta_{2}}+\left(\theta_{2} \phi_{1}\right)^{\beta_{3}}+\left\{\varepsilon_{1}\left[\phi_{2}+\left(\frac{\beta_{4}+\beta_{5}}{\beta_{2}} \theta_{1}^{*}-\frac{\phi_{2}}{\phi_{1}}\right) \phi_{1}\right]\right\}^{\beta_{4}}+\left\{\varepsilon_{2}\left[\phi_{2}+\left(\frac{\beta_{4}+\beta_{5}}{\beta_{2}} \theta_{1}^{*}-\frac{\phi_{2}}{\phi_{1}}\right) \phi_{1}\right]\right\}^{\beta_{5}}
$$

Similarly, expression (22) denoted an optimal ratio of transfer payments and productive expenditures, which is increasing with the contribution of the total expenditures of governments $\left(\beta_{4}+\beta_{5}\right)$, decreasing with the contribution of productive expenditures of the state-level government $\beta_{2}$ and the tax ratio between governments $\phi_{2} / \phi_{1}$. That means a greater contribution of the local-level government to the output absorbs more transfer payments from the state-level government, which implies a higher degree of fiscal decentralization.

\subsection{Fiscal Decentralization}

Under the assumptions that the total government expenditures are financed by tax, the portion that the locallevel government shared, i.e. the parameter $\phi_{2}$ in (4), implies the degree of fiscal decentralization among governments. A change of it will also have an impact on the steady-state growth rate. 
To show this, we chould differentiate both parts of (12) with respect to $\phi_{1}$ (noticed that $\phi_{1}=1-\phi_{2}$ ) and evaluating the resulting expression at $\partial G / \partial \phi_{1}=0$ yields

$$
\frac{\phi_{2}^{*}}{\phi_{1}^{*}}=\frac{\left(\beta_{4}+\beta_{5}\right)-\theta_{3}\left(1-\beta_{1}\right)}{\left(\beta_{2}+\beta_{3}\right)}
$$

Expression (25) denoted an optimal tax ratio shared between the state-level government and the local-level government, which is increasing with the contribution of the total expenditures of governments $\left(\beta_{4}+\beta_{5}\right)$, decreasing with the portion of transfer payments $\left[\theta_{3}\left(1-\beta_{1}\right)\right]$ and the contribution of the expenditures of the statelevel government. Expression (25) implies that a greater contribution of the expenditures of the local-level government to the output compared with that of the state-level government demands a higher degree of fiscal decentralization to maximize the long-run economic growth.

A simplier expression of (25) considers the condition of no transfer payments. Let $\beta_{l}=\left(\beta_{4}+\beta_{5}\right)$ denote the contritution of expenditures of the local-level government to the output, $\beta_{c}=\left(\beta_{2}+\beta_{3}\right)$ denote the contribution of the expenditures of the state-level government, $\phi=\phi_{2}$ and $\phi_{1}=(1-\phi)$. Without transfer payments, (25) is simplified as

$$
\phi^{*}=\frac{\beta_{l}}{\beta_{l}+\beta_{c}}
$$

Expression (26) implies that without transfer payments, an optimal degree of fiscal decentralization equals to the ratio between contributions of expenditures from different level governments. And a steady-state growth rate $G^{*}$ satisfying (26) can be denoted as

$$
G^{*}=G\left(\phi^{*}\right)
$$

Fig. 2 shows an "Inverted U-shape" relationship between fiscal decentralization and the steady-state growth rate under the condition of no transfer payments.

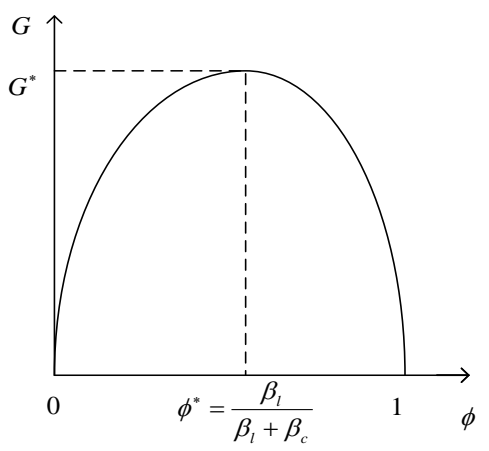

Fig.2 The impact of fiscal decentralization

As the degree of fiscal decentralization increases from zero to one, the long-run growth rate increases at first and arrived at the maximum denoted by (27), then it decreases eventually. The implication is obvious. A lower degree of fiscal decentralization constrains the power of the local-level government, while a greater degree of 
fiscal decentralization increases the externality costs of public goods provided by each local-level government. The optimal degree of fiscal decentralization are denoted by (26).

\section{Conclusions}

In our model, two levels of governments contributed to the output as their productive and non-productive expenditures, as well as transfer payments from the higher-level government to the lower-level government going into a Cobb-Doglas production function. Comparative static analysis showed that, on the balanced growth path, there was an "Inverted U-shaped" relationship between the tax rate and the long-run economic growth, so was the relationship between the degree of fiscal decentralization and the long-run economic growth. Meanwhile, optimal ratios between productive and non-productive expenditures of two levels of governments, between transfer payments and other parts of expenditures of the state-level governments are needed to maximize the long-run economic growth.

\section{References}

[1] R. Ram, "Government Size and Economic Growth: a New Framework and some Evidence form Crosssection and Time-series Data". University of Virginia Law Review, Vol 76, pp.191-203, 1986.

[2] D. Aschauer. "Is Public Expenditure Productive?" Journal of Monetary Economics, Vol 23, pp. 177-200, 1989.

[3] R. Barro. "Government Spending in a Simple Model of Endogenous Growth". Journal of Political Economy, Vol 98, pp.103-125, 1990.

[4] R.M. Solow. "A Contribution to the Theory of Economic Growth". Quarterly Journal of Economics, Vol 70, pp.65-94, 1956.

[5] S. Devarajan, V. Swaroop \& H. Zou. "The Composition of Public Expenditures and Economic Growth". Journal of Monetary Economic, Vol 37, pp.313-344, 1996.

[6] D. Xie, H. Zou \& H. Davoodi. "Fiscal Decentralization and Economic Growth in the United States". Journal of Urban Economics, Vol 45, pp.228-239, 1999.

[7] N. Akai, \& M., Sakata, "Fiscal Decentralization Contributes to Economic Growth: Evidence from Statelevel Cross-section Date for the United States", Journal of Urban Economics, Vlo 52, pp.93-108, 2002.

[8] T. Zhang \& H. Zou. "The Growth Impact of Intersectional and Intergovernmental Allocation of Public Expenditure: with Applications to China and India”. China Economic Review, Vol 12, pp.58-81, 2001. 